\title{
DESENVOLVIMENTO HUMANO E ECONÔMICO NO TRABALHO INFORMAL DAS FEIRAS MÓVEIS
}

SANTOS, A.L.S. ${ }^{\text {; ALENCAR, R. V. }}{ }^{2}$ \& CAVALCANTE, L. C. ${ }^{3}$

${ }^{1}$ Graduanda em Administração pela Universidade Federal do Ceará. Bolsista da ação extensionista. E-mail: liviasantos948@gmail.com; ${ }^{2}$ Mestre em Direito pela Universidade Federal do Ceará. E-mail: rafaelvieira93@ hotmail.com; ${ }^{3}$ Doutora em Sociologia pela Universidade

Federal do Ceará. Mestre em Direito Constitucional e Teoria do Estado pela Universidade de Fortaleza. Coordenadora da ação extensionista. E-mail: laracapelo@hotmail.com.

Artigo submetido em setembro de 2018 - DOI 10.32356/exta.v20.n2.33555

\section{RESUMO}

O comércio de rua, compreendido como atividade informal executada por muitos feirantes, camelôs e demais indivíduos com trabalhos semelhantes, também existente nas feiras móveis, têm sido utilizado significantemente como meio de garantia à sobrevivência na busca pelo sustento na atual situação socioeconômica do país, sendo gerador de empregabilidade e renda. Contudo, a informalidade tem impedido que muitos desses indivíduos trabalhem dignamente por não alcançarem direitos que só podem ser usufruídos por meio da formalização do trabalho. Desse modo, este artigo objetiva analisar os fatores que levam a resistência de alguns feirantes à formalização trabalhista, por exemplo, a escassez de conhecimento acerca dessa formalização, por uma parcela significante de feirantes, somado à utilidade da Tecnologia da Informação como ferramenta disseminadora de informações e no desenvolvimento do trabalho do pequeno empreendedor na busca pelo Desenvolvimento Humano e Crescimento Econômico no comércio de rua, situado nos bairros de Fortaleza, como Cidade 2000 e Praia do Futuro. Para a concretização do presente estudo, utilizou-se de pesquisas bibliográficas e da compilação de dados advindos da contagem e da aplicação de questionários nas duas feiras mencionadas.

PALAVRAS-CHAVE: Informalidade; Escassez de Informações; Tecnologia da Informação; Pequeno Empreendedor.

\section{HUMAN AND ECONOMIC DEVELOPMENT IN THE INFORMAL WORK OF MOBILE FAIRS}

\section{ABSTRACT}

Street commerce, understood as an informal activity performed by many marketers, street vendors and other individuals with similar work, also existing in mobile fairs, has been used significantly as a means of survival in the search for sustenance in the current socioeconomic situation of the country. And it is a job and income generator. However, informality has prevented many of these individuals from working with dignity because they do not achieve rights that can only be enjoyed through the formalization of work. Thus, this article aims to analyze the factors that lead the resistance of some marketers to labor formalization, for example, the lack of knowledge
\end{abstract}

about this formalization, by a significant portion of marketers, adding the usefulness of Information Technology as a tool for disseminating information. And work development of the little entrepreneur in the search for Human Development and Economic Growth in the street commerce, located in the neighborhoods of Fortaleza, such as Cidade 2000 and Praia do Futuro. For the accomplishment of the present study, we used bibliographical research and the data compilation from counting and the application of questionnaires in the two mentioned fairs.

KEYWORDS: Informality; Scarcity of information; Information Technology; Little entrepreneur.

\section{INTRODUÇÃO}

Conforme a Organização Internacional do Trabalho (OIT), o índice de desemprego no Brasil deverá cair dos 12,9\% registrados em 2017 para 11,9\% neste ano; apesar da diminuição, os empregos vulneráveis que geralmente não se tem acesso à seguridade social 
irão levemente crescer, passando de 25,3\% para 25,8\%; onde esse crescimento é reflexo da crise econômica no mercado de trabalho (BRASIL. DW apud OIT, 2018). Logo, uma das formas de representação dessa modalidade de empregos vulneráveis pode ser representada pelo comércio de rua, no qual muitos trabalhadores praticam suas atividades tidas como informais sem a devida regulamentação do trabalho por parte do Governo. Em vista disso, o aumento contínuo da prática do comercio de rua é tido como um fenômeno de alta notoriedade nas localidades urbanas do Brasil (MAFRA, 2007).

Nesse contexto, as feiras móveis, como um dos âmbitos de grande e notória inserção da informalidade, têm sido a saída para muitos cidadãos desempregados, tornando-se uma das fontes de empregabilidade e de renda no contexto socioeconômico atual. Entretanto, o desempregado, na tentativa de se estabelecer na economia informal, passa a ter perdas consideráveis na sua cidadania e na sua dignidade, visto que são maiores as dificuldades no contexto de informalidade para que se estabeleça como sujeito coletivo, por intermédio de uma vida organizada sindicalmente, por exemplo (HORTA, 2001).

Nesse sentido, apesar dos feirantes informais não obterem direitos necessários para se ter um trabalho e uma vida mais digna enquanto cidadão, ainda há uma resistência, por parte desses trabalhadores, à formalização do trabalho. Desse modo, a escassez de conhecimento acerca dessa legalização trabalhista é um dos fatores que os induzem a permanecer na informalidade. Tendo isso em vista, é válida a utilização dos métodos possíveis e diversificados quanto ao fornecimento de informações necessárias sobre a temática abordada.

Nesse conjuntura, pode-se destacar a Tecnologia da Informação(TI) como sendo uma dessas fontes que pode ser designada como o agrupamento de recursos tecnológicos e computacionais para fornecimento e uso da informação que se baseia nos seguintes elementos: software e seus recursos; gestão de dados e informações; hardware e seus dispositivos periféricos e sistemas de telecomunicações (REZENDE e ABREU, 2000).

Portanto, o estudo em questão é advindo do Projeto de Extensão intitulado "Feirante Empreendedor: Tecnologia da Informação, Desenvolvimento Humano e Crescimento Econômico no Comércio de Rua", tendo como objetivo compreender o contexto da informalidade no comércio de rua junto a disseminação de informações acerca da formalização do trabalho nas feiras móveis em Fortaleza, que transitam pelos bairros Cidade 2000 e Praia do Futuro, em diferentes dias da semana, no sentido de impulsionar os feirantes 
informais que não possuem conhecimento e que se mostram resistentes quanto ao assunto a se tornarem trabalhadores legalizados e assim passar a usufruir de direitos e a viver com dignidade e cidadania merecida cooperando para seu desenvolvimento como pessoa em sociedade e para o seu crescimento econômico e local com base nos princípios constitucionais que serão relatados a seguir.

\section{DIRETRIZES GERAIS DO DESENVOLVIMENTO HUMANO E CRESCIMENTO ECONÔMICO NO COMÉRCIO DE RUA}

O Desenvolvimento Humano e o Crescimento Econômico são fundamentados em princípios constitucionais. Como infere a Constituição Federal de 1988:

\footnotetext{
Art. $1^{\circ}$ A República Federativa do Brasil, formada pela união indissolúvel dos Estados e Municípios e do Distrito Federal, constitui-se em Estado Democrático de Direito e tem como fundamentos:

[...] III - a dignidade da pessoa humana;

IV - os valores sociais do trabalho e da livre iniciativa [...]

[...]

Art. 170. A ordem econômica, fundada na valorização do trabalho humano e na livre iniciativa, tem por fim assegurar a todos existência digna, conforme os ditames da justiça social, observados os seguintes princípios:

[...] IV - livre concorrência[...] (BRASIL,1988)
}

Como visto acima, dois dos princípios em que o Desenvolvimento Humano está fundamentado são a Dignidade da Pessoa Humana e os Valores Sociais do Trabalho, os quais foram colocados como alguns dos fundamentos essenciais da República Federativa elencados pela Constituição de 1988 no artigo $1^{\circ}$ inciso III e IV, respectivamente (BRASIL,1988).

Nessa perspectiva, a dignidade é um valor espiritual e moral intrínseco à pessoa, a qual é manifestada exclusivamente na autodeterminação consciente e responsável da própria vida, além da pretensão ao respeito advindos dos demais indivíduos, no qual todo estatuto jurídico deve garantir, de maneira que, possam ser realizadas limitações a prática dos direitos fundamentais além de nunca menosprezar a estima necessária que todas as pessoas enquanto seres humanos merecem (FINATI apud SARLET, 1996).

Segundo Finati (1996), a dignidade da pessoa está diretamente ligada aos valores sociais do trabalho, onde a dignidade da pessoa está relacionada com a respeitabilidade que o cidadão possui no meio em que vive. Ademais, também ressalta que o trabalho dignifica a pessoa na medida que permite sua autoafirmação no âmbito familiar e na sociedade, permitindo, ainda, participar integralmente da vida social além de ser um fator de civilização 
e de progresso. Desde o surgimento da humanidade na terra, o trabalho tem sido o grande fator que garante a estabilidade e o progresso dos grupos sociais.

Referente ao Crescimento Econômico, dois de seus princípios constitucionais são a livre iniciativa (Art. $1^{\circ}$ inciso IV) e a livre concorrência (Art. 170 inciso IV). Nesse sentido, o artigo $170^{\circ}$ da Constituição Federativa do Brasil salienta que a ordem econômica, fundada na valorização do trabalho e na livre iniciativa, visa garantir existência digna a todos, de acordo com as leis da justiça social seguindo alguns princípios, onde um deles é a livre concorrência (BRASIL, 1988).

Dessa maneira, baseado nos dois artigos mencionados anteriormente, nota-se que os princípios de livre iniciativa e livre concorrência estão correlacionados. Assim, conforme Moura (2012), o princípio da livre iniciativa está relacionado com o ideal de liberdade econômica, e seu reconhecimento pela ordem jurídica objetiva garantir aos indivíduos a livre escolha da atividade que queiram desenvolver para seu sustento além de limitar a ação do Estado relativo ao campo das atividades econômicas dos agentes. Assim, esse princípio prediz que a todos é assegurado a livre execução de qualquer atividade econômica, com ou sem a autorização dos órgãos públicos. Portanto, os trabalhadores devem ser livres para produzir e colocar seus produtos no mercado, práticas que conseguem desenvolver devido ao princípio da livre concorrência que assegura a todos a liberdade de mercado.

\subsection{EMPREENDORISMO NO CONTEXTO DA INFORMALIDADE E A ESCASSEZ DE CONHECIMENTO DE ALGUNS FATORES RELATIVO A FORMALIZAÇÃO DO TRABALHO POR PARTE DE ALGUNS FEIRANTES}

$\mathrm{O}$ crescimento das cidades junto ao aumento populacional nos espaços urbanos e a consequente crise do desemprego são fatos ocorrentes e notórios nos dias de hoje. Por conta desses elementos, o trabalho informal com grande presença nas feiras móveis, também foi ampliado, visto que tem sido uma das alternativas para grande parte dos desempregados do País. Portanto, "[...] trata-se de uma informalidade derivada da nova dinâmica econômica" (Santos, 2008, p.154).

Nesse lógica, a feira seja ela móvel ou fixa é um elemento essencial da atividade lucrativa e do abastecimento dos habitantes de uma cidade além de ser vista como um local de mercado no qual o comerciante é o responsável pelo transito de mercadorias entre localidades 
distintas (Max Weber, 1979).

Nesse âmbito, Souza e Feijó (2006), inferem que o emprego informal é o trabalho que a pessoa pratica sem possuir acesso aos direitos trabalhistas além de não haver legalização por meio de documentos, não tendo vínculo com qualquer empresa, estendendo a maneira de trabalho em termos de precariedade em seus variados ramos.

Desse modo, o alto índice de desemprego no país ocasiona a informalidade, onde muitos indivíduos abrem seu próprio negócio (empreendimentos) como meio de sobrevivência ou de melhoramento financeiro, porém de modo ilegal sem acesso aos direitos necessários para execução de um trabalho mais digno provenientes da formalização do trabalho.

Ademais, levando em consideração os empreendimentos que muitas pessoas abrem como meio de sobrevivência em meio ao alto índice de desemprego no país, também é válido ressaltar que, de acordo com Schumpeter (2012), atualmente, o empreendedor é tido com o impulsor da economia de um país, sendo atuante no que diz respeito a inovação e mudança além de ser o maior responsável pela criação de novas empresas junto a geração de empregabilidade.

Nesse contexto, segundo Marcondes (2000), o empreendedor é toda pessoa que identifica necessidades de clientes potenciais e cria uma empresa com uma oportunidade de negócio para satisfazê-las, podendo ser um empreendedor: o desempregado que se torna camelô, o técnico que cria uma fábrica ou o insatisfeito com o emprego que se demite e abre uma loja, o dentista que abre um consultório, dentre outros.

Sabe-se, também, que o empreendedorismo é um fenômeno cultural, e conforme Dolabela (1999), é fruto dos hábitos, práticas e valores das pessoas. O autor também infere que existem famílias mais empreendedoras do que outras, assim como cidades, regiões, países.

Nesse sentido, é relevante ressaltar que o empreendedorismo envolve desde o pequeno ao grande empreendedor, onde o menor é a base para se chegar ao maior empreendimento. Com base nisso, de acordo com o SEBRAE (2018), o pequeno empreendedor se encaixa nas características do Micro Empreendedor Individual (MEI), pois é o trabalhador que, conforme as Leis Complementares 123/06 e 128/08, trabalha por conta própria e legaliza-se como pequeno empresário, passando a ter CNPJ, facilitando assim a o que a abertura de conta 
bancária, o pedido de empréstimos e a emissão de notas fiscais; onde o MEI passa a ser enquadrado no Simples Nacional além de passar a ser isento aos tributos federais, tais como, Imposto de Renda, PIS, Confins, IPI e CSLL, tendo acesso a diversos direitos previdenciários, como auxílio-maternidade, auxílio doença, aposentadoria, dentre outros.

Assim, para o trabalhador se tornar um MEI terá que seguir os seguintes requisitos: faturar até $\mathrm{R} \$ 81.000,00$ por ano ou $\mathrm{R} \$ 6.750,00$ por mês; não ter participação em outra empresa como sócio ou titular; ter no máximo um empregado contratado que receba o saláriomínimo ou o piso da categoria.

Entretanto, segundo dados, que serão relatados mais adiante, da pesquisa feita nas feiras situadas nos bairros Cidade 2000 e Praia do Futuro em Fortaleza, por intermédio do projeto intitulado "Feirante Empreendedor: Tecnologia da Informação, Desenvolvimento Humano e Crescimento Econômico no Comércio de Rua", muitos feirantes se mostram resistentes à formalização do trabalho é , onde um dos fatores que cooperam para essa situação é o desconhecimento de alguns feirantes relativo ao que tem por trás de fato dessa legalização trabalhista, levando em consideração que muitos deles têm em mente que serão apenas cobrados, pois mais adiantes será visto que muitos desses trabalhadores não conhecem os benéficos (Direitos) advindos da formalização e que mesmo com esse "medo" de ter apenas deveres ao deixar de lado a informalidade, possuem interesse em ter conhecimento sobre o assunto.

Portanto, percebe-se que há um impedimento de um trabalho digno, por parte dos feirantes ilegais, quanto a utilização de vários direitos proporcionados após se tornar MEI, por exemplo, direitos previdenciários que ajudariam relativo à saúde e futuramente quando não pudessem ou não quisessem mais trabalhar, quando idosos, pois dois dos inúmeros direitos do MEI é o de auxílio a doença e a aposentadoria, na árdua busca pela garantia de estabilidade e progresso em sociedade por intermédio da procura e do alcance de sucesso em seus negócios, o qual contribui para o crescimento econômico no comercio de rua.

\subsection{A TECNOLOGIA DA INFORMAÇÃO COMO FERRAMENTA DISSEMINADORA DE INFORMAÇÕES E CONHECIMENTO E AUXILIO AO DESENVOLVIMENTO DA ATIVIDADE DO PEQUENO EMPREENDEDOR}

A Tecnologia da Informação (TI) pode ser compreendida como sendo hardware, 
software e pessoas envolvidas responsáveis pela obtenção, armazenamento, tratamento, comunicação e disponibilização de informações (Albertin,2004).

Nesse cenário, a TI proporciona vários métodos para fornecimento de informações e conhecimentos com conteúdos específicos para determinado público alvo. Tendo como exemplo, os aplicativos, sendo alguns deles:

- Aplicativos de redes sociais (Facebook, Instagram, Whatsapp) os quais são utilizados para conversar com amigos e familiares, para se manterem informados com as notícias do mundo todo;

- $\quad$ Aplicativo de Transporte (Uber, Cabify, 99 pop), onde quem deseja se deslocar de um lugar para outro se comunica com os motoristas pelo aplicativo que informa quanto tempo vai demorar pra chegar e o valor da corrida, dentre outras utilidades;

- Aplicativo de Bancos (Banco do Brasil, Caixa Econômica, Itaú, Bradesco, Santander) no qual o cliente tem acesso a sua conta podendo ver seu saldo, emitir extratos, dentre outras funções;

- Aplicativos de Compras/Vendas (OLX, Barato Coletivo, Mercado Livre, Ifood), onde as pessoas podem divulgar seus produtos a um maior número de pessoas e os que desejarem comprar o produto exposto entra em contato e efetua a compra. Portanto, nota-se que tal ferramenta repassa informações com conteúdos específicos para determinado público alvo.

Nessa mesma linha de raciocínio, tendo em vista a utilidade dos aplicativos e a questão do desconhecimento referente a formalização do trabalho, o projeto já citado desenvolvido por acadêmicos da Universidade Federal do Ceará vem elaborando um aplicativo especificamente para os feirantes, tendo como conteúdo a temática abordada, isto é, informações sobre a formalização do trabalho dando enfoque aos direitos e deveres que os trabalhadores formais têm e que os informais podem ter além de informações e dicas para auxiliar no desenvolvimento de seu trabalho e cooperar para o sucesso de seus negócios, levando em consideração o interesse por parte desses trabalhadores em utilizá-lo, o que será mostrado mais adiante na compilação de dados referente ao uso da TI pelos feirantes somada a possíveis medidas que podem auxiliar na disseminação de informações com a utilização da TI.

Para mais, a TI pode ser uma ferramenta de grande valia para o trabalho não só do grande como do pequeno empreendedor, visto que pode ser uma ferramenta relevante na execução de seu trabalho. Com base nisso, Albertin (2001) ressalta algumas contribuições da Tecnologia da Informação, sendo algumas delas: 
1. RELACIONAMENTO: As empresas se comunicam com seus clientes por intermédio de diversas mídias, visto que por muito tempo os meios tecnológicos vêm mudando de modo significante o olhar tradicional de mídia relativo ao marketing, à compra e à venda. Nesse sentido, os ambientes intermediado por computadores, como a internet possibilitam outro modo de chegar aos consumidores junto ao fato de estimular compradores e vendedor a desenvolver seu uso, por viabilizar melhoria na comunicação com sua clientela, maior eficiência nas relações de vendas além de proporcionar um mercado mais atrativo.

2. INOVAÇÃO DE PRODUTOS: As novas regras no ambiente empresarial atribuídos pela Tecnologia da Informação podem ser entendidas, como a flexibilidade e o poder de resposta; onde a estratégia de produção e venda referente a era industrial foi trocada pela de sentir e responder as mudanças de acordo com a necessidade e singularidades dos clientes, de modo preciso.

3. NOVOS CANAIS DE VENDA E DISTRUBUIÇÃO: Os sistemas de TI simbolizam um novo meio de vendas e de compartilhamento para produtos que novos ou que já existem devido ao alcance direto e a natureza bidirecional na comunicação de informações desses sistemas.

4. PROMOÇÃO DE PRODUTOS: A Tecnologia da Informação pode proporcionar melhorias relativo a promoção dos produtos e serviços através de um contato direto, rico em informações e que interaja com os clientes.

5. NOVAS OPORTUNIDADES DE NEGÓCIOS: Os sistemas de TI com a alteração nas estruturas dos setores, possibilitam o aparecimento de novos modelos de negócios, fundamentados no significante número disponível de informações e sua distribuição direta aos clientes e fornecedores.

6. ECONOMIA DIRETA: A Tecnologia da Informação pode minimizar, de modo significante, os custos de comercialização, distribuição e serviços aos clientes, por intermédio da utilização da infraestrutura digital pública e compartilhada, por exemplo, a internet, comparada a uma infraestrutura própria.

7. INFRAESTRUTURA PÚBLICA: A forma de garantir acesso ao ambiente digital da Tecnologia da Informação é através da criação e da utilização de uma infraestrutura pública, que possua mecanismos de acesso, estruturas de alcance local e redes globais de informações.

Ainda é relevante ressaltar as duas últimas contribuições da Tecnologia da Informação mencionadas por Albertin: Economia Direta e Infraestrutura Pública que remetem ao acesso ao ambiente digital da TI por intermédio de suporte público proporcionando mecanismos de acesso para o alcance de informações. Desse modo, pode-se citar como exemplo, o "wifi" gratuito em vários locais, como praças públicas e até mesmo em algumas feiras situadas em Fortaleza, onde muitos utilizam a TI como ferramenta no trabalho, possibilitando assim a inibir gastos de comercialização além de auxiliar nos serviços prestados aos clientes. Contudo, essa infraestrutura de acesso às redes globais de informação nas feiras móveis ainda é mínimo, como é o caso das feiras Cidade 2000 e Praia do futuro, em Fortaleza. 


\section{MATERIAIS E MÉTODOS}

Primeiramente, utilizou-se a pesquisa bibliográfica visto que "o conhecimento teórico adequado acarreta rigor conceitual, análise acurada, desempenho lógico, argumentação diversificada, capacidade explicativa" (DEMO, 1994, p. 36), a qual foi efetuada com base em material já elaborado, como livros e artigos científicos (GIL, 2008), sobre o contexto da informalidade nas feiras de Fortaleza, mais especificamente na Praia do Futuro, onde há a presença notória de trabalhadores informais além da utilidade da tecnologia da informação para disseminação de informações acerca da formalização do trabalho somado as diretrizes gerais do Desenvolvimento Humano e Crescimento Econômico no comércio de rua ligadas ao trabalho digno do pequeno empreendedor.

Em seguida foi feita a compilação de dados que foi executada a partir de informações advindas da realização de contagens das barracas (formais e informais); e pela aplicação de questionários com indagações acerca da Tecnologia da informação nas feiras situadas nos bairros Praia do Futuro e Cidade 2000, presencialmente, pelos demais membros do projeto Feirante Empreendedor, sendo possível a partir de então deduzir se a TI pode ajudar ou não quanto a informalidade $\mathrm{e}$ as vertentes sociais elencadas ao trabalho referente ao desenvolvimento humano e ao auxílio dessa ferramenta para o crescimento econômico no comércio de rua.

\subsection{QUANTIDADE DE BARRACAS E DE FEIRANTES (FORMAIS E INFORMAIS) NAS DUAS FEIRAS EM QUESTÃO}

Inicialmente, é importante ressaltar que a documentação que possui a relação do número de feirantes cadastrados (legais/formais) está sobre responsabilidade da Prefeitura de Fortaleza. Entretanto, não foi possível adquirir tais informações. Diante disso, foi realizado a contagem nas duas feiras e a partir de então foi realizada a seguinte compilação: 
Tabela 1: Dados da Contagem na feira- Cidade 2000

\begin{tabular}{|c|c|c|}
\hline FEIRAS & BARRA CAS & FEIRANTES \\
\hline \multirow{3}{*}{ CIDADE 2000 } & $\mathrm{N}^{\circ}$ de Barracas Formais: 97 & $\mathrm{~N}^{\circ}$ de Feirantes Formais: 149 \\
& $\mathrm{~N}^{\circ}$ de Barracas Informais: 0 & $\mathrm{~N}^{\circ}$ de Feirantes Informais: 0 \\
& Total de Barracas (Formais + Informais): & Total de Feirantes (Formais + Informais): \\
& 97 Barracas Formais & 149 Feirantes Formais \\
\hline & $\mathrm{N}^{\circ}$ de Barracas Formais: 105 & $\mathrm{~N}^{\circ}$ de Feirantes Formais: 206 \\
PRAIA DO & $\mathrm{N}^{\circ}$ de Barracas Informais: 28 & $\mathrm{~N}^{\circ}$ de Feirantes Informais: 28 \\
FUTURO & Total de Barracas (Formais + Informais): & Total de Feirantes (Formais + Informais): \\
& 133 & 234 \\
\hline
\end{tabular}

Fonte: Adaptada pelo autor (2018).

Como mostra a tabela 1 a feira- Cidade 2000 só possui barracas formais, sendo classificadas dessa forma por possuírem estrutura adequada e autorização da prefeitura para sua existência, assim como seus donos para execução de seus trabalhos, isto é, de poderem trabalhar legalmente, sendo classificados, assim, como feirantes formais.

Considera-se que as barracas informais são as que não possuem estrutura adequada, nem autorização da Prefeitura para sua existência, onde as pessoas que trabalham nelas não possuem tal autorização para realizar suas atividades econômicas de modo legal. Dessa forma, o critério de classificação desses trabalhadores como feirantes informais foram aqueles que estavam a margem das barracas formais, por exemplo, vendedores ambulantes que não têm uma estrutura física montada que muitas vezes expõem suas mercadorias em carrinhos, tapetes/ lonas/ panos ou circulam nas feiras segurando seus produtos. Assim sendo, estima-se, que as 28 barracas informais correspondem a 21,0\% das barracas presentes na feira- Praia do Futuro, e as 105 barracas com características de barracas formais-79,0\%. Ademais, referente a quantidade de feirantes, estima-se que $12 \%$ dos feirantes 234 feirantes são formais e $88 \%$ deles, formais.

\subsection{O USO DA TECNOLOGIA DA INFORMAÇÃO POR PARTE DOS FEIRANTES}

O levantamento de tais informações é decorrente da coleta de dados relativo às respostas dos feirantes a algumas das indagações presentes no questionário aplicado nas duas feiras em questão. Portanto, os dados da feira Praia do Futuro é correspondente ao feedback advindo de 30 feirantes na feira- Cidade 2000; e de 63 feirantes na feira- Praia do Futuro, como mostra a tabela abaixo: 
Tabela 2: Dados correspondente as respostas dos feirantes às indagações do questionário sobre TI

\begin{tabular}{|c|c|c|}
\hline PERGUNTAS & $\begin{array}{l}\text { FEIRA-CIDADE } 2000 \\
\text { (30 Feirantes) }\end{array}$ & $\begin{array}{l}\text { FEIRA- PRAIA DO FUTURO } \\
\text { (63 Feirantes) }\end{array}$ \\
\hline $\begin{array}{l}\text { Conhece a tecnologia da } \\
\text { informação? }\end{array}$ & $\begin{array}{l}\text { 26-Conhece }(86,7 \%) \\
\text { 03-Não conhece }(13,3 \%)\end{array}$ & $\begin{array}{l}\text { 19-Conhece }(84,1 \%) \\
\text { 44-Não conhece }(15,9 \%)\end{array}$ \\
\hline $\begin{array}{l}\text { Já usou algumas ou usa algumas } \\
\text { dessas T.I: Aplicativos de Redes } \\
\text { Sociais; de Transporte; de Bancos; } \\
\text { de Compras/Vendas? }\end{array}$ & $\begin{array}{l}\text { 22-Já usou ou utiliza } 1 \text { ou mais } \\
\text { aplicativo }(73,3 \%) \\
\text { 08-Não utiliza }(26,7 \%) \\
\text { 03-Usa ou já usou todos os } \\
\text { aplicativos }(13,6 \%) \\
\text { 19-Usa ou já usou um ou mais } \\
\text { dos aplicativos }(86,4 \%)\end{array}$ & $\begin{array}{l}\text { 0-Já usou ou utiliza } 1 \text { ou mais aplicativo } \\
(63,5 \%) \\
\text { 23-Não utiliza }(36,5 \%) \\
\text { 05-Usa ou já usou todos os aplicativos } \\
(12,5 \%) \\
\text { 35-Usa ou já usou um ou mais dos } \\
\text { aplicativos }(87,5 \%)\end{array}$ \\
\hline $\begin{array}{l}\text { Utiliza alguma TI no } \\
\text { desenvolvimento de seu trabalho? }\end{array}$ & $\begin{array}{l}\text { 2-Utiliza }(40,0 \%) \\
\text { 18-Não utiliza }(60,0 \%)\end{array}$ & $\begin{array}{l}\text { 19-Utiliza }(30,2 \%) \\
\text { 44-Não utiliza }(69,8 \%)\end{array}$ \\
\hline $\begin{array}{l}\text { Com que frequência utiliza a TI na } \\
\text { sua vida pessoal: } 1 \text { ou } 2 \text { dias; } 3 \text { ou } \\
4 \text { dias; } 5 \text { ou mais dias ou não } \\
\text { utiliza? }\end{array}$ & $\begin{array}{l}\text { 0- Um ou dois dias }(0 \%) \\
\text { 03- Três ou quatro dias }(10,0 \%) \\
\text { 19- Cinco ou mais dias }(63,3 \%) \\
\text { 08- Não utiliza }(26,7 \%)\end{array}$ & $\begin{array}{l}\text { 03-Um ou dois dias }(4,8 \%) \\
\text { 02-Três ou quatro dias }(3,2 \%) \\
\text { 36-Cinco ou mais dias }(57,1 \%) \\
\text { 22-Não utiliza }(34,9 \%)\end{array}$ \\
\hline $\begin{array}{l}\text { Com que frequência utiliza a TI no } \\
\text { desenvolvimento do seu trabalho: } \\
1 \text { ou } 2 \text { dias; } 3 \text { ou } 4 \text { dias; } 5 \text { ou mais } \\
\text { dias ou não utiliza? }\end{array}$ & $\begin{array}{l}\text { 03-Um ou dois dias }(10,0 \%) \\
\text { 06-Três ou quatro dias }(20,0 \%) \\
\text { 05-Cinco ou mais dias }(16,7 \%) \\
\text { 16-Não utiliza }(53,3 \%)\end{array}$ & $\begin{array}{l}\text { 06-Um ou dois dias }(9,5 \%) \\
\text { 04-Três ou quatro dias }(6,3 \%) \\
\text { 08-Cinco ou mais dias }(12,7 \%) \\
\text { 45-Não utiliza }(71,4 \%)\end{array}$ \\
\hline $\begin{array}{l}\text { Teria interesse de utilizar um } \\
\text { aplicativo desenvolvido para } \\
\text { auxiliar o feirante no } \\
\text { desenvolvimento de seu trabalho? }\end{array}$ & $\begin{array}{l}\text { 18-Tem interesse }(60,0 \%) \\
12-N a ̃ o \text { tem interesse }(40,0 \%)\end{array}$ & $\begin{array}{l}\text { 30-Tem interesse }(47,6 \%) \\
33-N a ̃ o \text { tem interesse }(52,4 \%)\end{array}$ \\
\hline $\begin{array}{l}\text { Teria interesse de utilizar um } \\
\text { aplicativo desenvolvido para } \\
\text { informar o feirante acerca dos seus } \\
\text { direitos? }\end{array}$ & $\begin{array}{l}20 \text {-Tem interesse }(66,7 \%) \\
10 \text {-Não tem interesse }(33,3 \%)\end{array}$ & $\begin{array}{l}\text { 30-Tem interesse }(47,6 \%) \\
33-N a ̃ o \text { tem interesse }(52,4 \%)\end{array}$ \\
\hline
\end{tabular}

Fonte: Arquivo pessoal do autor 2018.

\section{RESULTADOS E DISCUSSÕES}

Por intermédio da análise da compilação dos dados da contagem feita nas duas feiras, percebe-se que a formalização se sobressai na feira- Cidade 2000 (I) relativo à informalidade, pois todas as barracas possuem características formais. Todavia, diferente desta, a feira-Praia do Futuro (II) possui um valor percentual significante de informalidade, pois a quantidade de barracas com particularidades pertencentes as não formais é equivalente a $21 \%$, assim como $12 \%$ dos trabalhadores têm atribuições relativas aos feirantes classificados como informais. 
Nesse sentido, é possível inferir, por intermédio dessas estimativas, que a feira tem sido um local muito utilizado para execução do trabalho informal o que é comprovado pelo número considerável de feirantes e barracas informais. Logo, o desconhecimento, por parte desses trabalhadores informais, acerca da formalização do trabalho como sendo um dos principais fatores contribuintes para a resistência e permanência dessas pessoas a esse cenário precisa de medidas eficazes para reverter essa situação já que a informalidade priva esses indivíduos de usufruir direitos provenientes de sua formalização enquanto trabalhador.

Ademais, relativo a tecnologia da informação, segundo a análise dos dados do retorno dos feirantes as perguntas do questionário, o percentual correspondente ao número de feirantes, possibilita inferir que é a maioria desses trabalhadores conhecem a TI, visto que apenas 13,3\% dos 30 feirantes da feira I e 15,9\% dos 63 trabalhadores da feira II alegaram não conhecer essa ferramenta.

Nessa situação, 26,7 \% dos 30 feirantes da feira I afirmaram nunca ter utilizado nenhum dos quatro tipo de aplicativos citados (de redes sociais, de transporte, de bancos, de compras/vendas); assim como os 36,5\% dos 63 trabalhadores da feira II. Ademais, 13,6\% dos 22 feirantes da feira- Cidade 2000 que inferiram utilizar uma ou mais TI, afirmaram já ter utilizado ou usar todas as TI's citadas, bem como 12,5\% dos 40 trabalhadores da feira- Praia do Futuro. Diante desses fatores, pode-se concluir que a maioria dos feirantes já usaram ou usam algum aplicativo. A seguir os dois gráficos mostrarão a utilização dos aplicativos pelos trabalhadores em ambas as feiras:

Gráfico 1: Utilização dos aplicativos na feira I- 30 feirantes

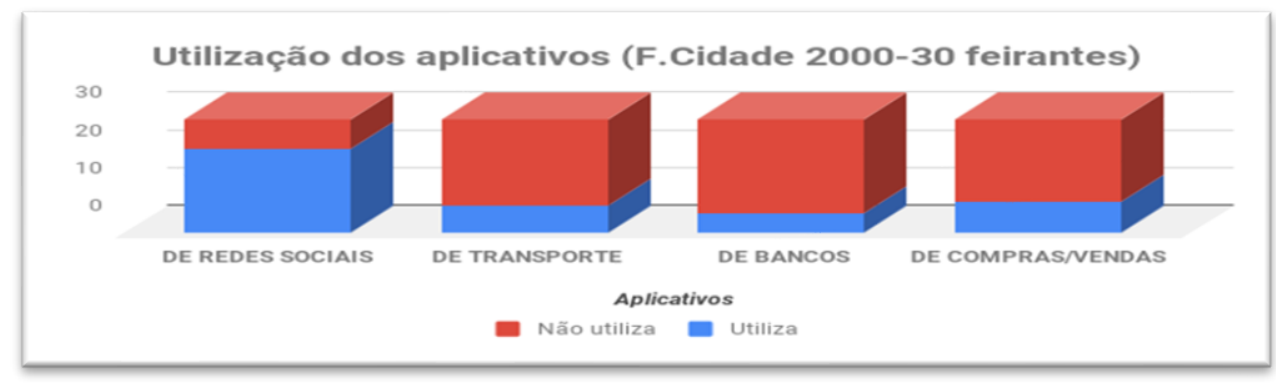

Fonte: Arquivo pessoal do autor (2018). 
Gráfico 2: Utilização dos aplicativos na feira II- 63 feirantes

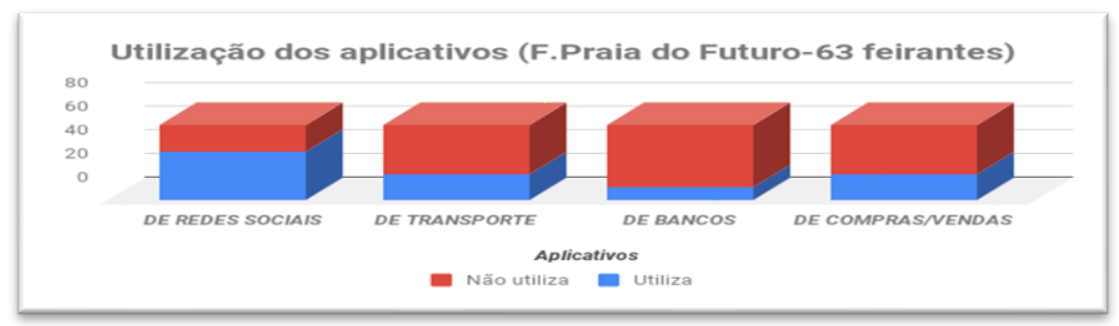

Fonte: Arquivo pessoal do autor (2018).

Os gráficos mostram que o aplicativo mais utilizado nas duas feiras são os aplicativos de redes sociais, visto que $73,3 \%$ dos trabalhadores da feira I inferiram utilizar algum desses aplicativos (Instagram, Facebook, Whatsapp) assim 63,5\% dos feirantes do comércio de rua II; sendo o segundo mais utilizado o aplicativo de compras e vendas, pois cerca de $26,7 \%$ desses trabalhadores da feira- Cidade 2000 e 33,3\% da feira- Praia do futuro declaram já terem utilizado algum desses aplicativos (OLX, Barato Coletivo, Mercado Livre, Ifood). Por isso, nota-se que grande maioria dos trabalhadores das duas feiras de Fortaleza conhecem a Tecnologia da informação e usufruem dessa ferramenta, o que é comprovado pelo percentual relativo ao uso dos aplicativos pelos feirantes.

Sabe-se também que a Tecnologia da Informação tem inúmeras utilidades, visto que pode ser usada na vida pessoal, mas também pode ser uma ferramenta de trabalho dos feirantes. Nesse sentido, pode-se apontar como exemplo as redes sociais que serve tanto para comunicação com familiares e amigos além de manter "antenado" os seus usuários relativo às notícias do país e do mundo quanto para divulgação de produtos, contato com o cliente, dentre outras possibilidades que essa ferramenta possibilita usufruir. Dessa forma, dos feirantes que afirmaram utilizar a TI na sua vida pessoal, 66,3\% desses trabalhadores na Feira I e 57,1\% na feira II alegaram utilizá-la frequentemente em uma faixa de 5 ou mais dias. Entretanto, 60,0\% dos 30 trabalhadores da feira I e 69,8\% dos 63 da feira II não utilizam a TI como ferramenta de trabalho, logo, é perceptível que a TI é pouco utilizada pelos feirantes nessa vertente.

Nessa perspectiva, também é relevante ressaltar acerca do desconhecimento por parte desses trabalhadores referente aos seus direitos enquanto feirantes formais, o qual é um fator causador da resistência e permanência de muitos feirantes na informalidade. Diante dessa situação, foi indagado, nas duas feiras, quanto ao interesse em utilizar um aplicativo criado 
especificamente para esse público de trabalhadores tanto formais quanto informais que fornecesse informações sobre direitos e deveres após a formalização de seu trabalho e que ao mesmo tempo auxiliasse no desenvolvimento de suas atividades econômicas com o fornecimento de conteúdos informativos e auxiliadores elaborados por acadêmicos nas áreas necessárias relativo aos fatores citados, como da área de administração, direito e contabilidade. Assim sendo, 50 dos 93 feirantes que responderam o questionário (20 dos 30 feirantes da feira- Cidade 2000 e 30 dos 63 trabalhadores da feira-Praia do Futuro), mostraram-se interessados em tal aplicativo ainda não existente. Número significante e que precisa ser levado em conta.

\section{CONCLUSÃO}

Designar o perfil dos trabalhadores nas feiras Cidade 2000 e Praia do Futuro permite a elucidação da realidade existente no comércio de rua. Assim, essa ação é primordial para inibição de um pensamento mistificado sobre a visão da ilegalidade do trabalho nas feiras, isto é, da imagem do feirante como trabalhador informal. Soma-se a isso as possíveis medidas paliativas e políticas públicas que podem ser tomadas em meio ao contexto de informalidade no comércio de rua de Fortaleza.

Nesse sentido, faz-se necessário uma ação conjunta de órgãos que possuam algum vínculo com a temática abordada, como a Prefeitura e o SEBRAE, ajudando a entidade acadêmica através do projeto Feirante Empreendedor a disseminar informações referente a informalidade afim de inibi-la. O Projeto de Extensão intitulado "Feirante Empreendedor: Tecnologia da Informação, Desenvolvimento Humano e Crescimento Econômico no comércio de Rua" constituído por acadêmicos e professores dessa instituição educacional tem como uma de suas ações a elaboração de um aplicativo voltado especificamente para o pequeno empreendedor a fim de informá-lo acerca de seus direitos e ao mesmo tempo fornecer informações que auxilie no desenvolvimento e sucesso de seus negócios, onde esses conteúdos são elaborados por estudantes da área de Administração, Contabilidade e Direito em parceria com uma entidade relacionada a Tecnologia da Informação.

Assim, para obter um resultado ainda mais significante, a pesquisa sugere que instituições como o SEBRAE e o Município de Fortaleza desenvolvam ações em parceria com o projeto mencionado no sentido de informar os feirantes, especialmente na feira- Praia do 
Futuro, onde há um número considerável de trabalho informal, como mostram as estimativas já relatadas. As ações sugeridas poderiam ocorrer na modalidade de palestras e eventos interativos e descontraídos que mostrassem a real importância da formalização do trabalho, tirando as dúvidas dos feirantes quanto ao assunto, além de divulgar o aplicativo, levando em consideração que muitos feirantes se mostraram interessados em utilizá-lo como visto anteriormente.

Além do mais, outro fator e política pública necessária e cabível ao Município de Fortaleza seria a expansão de redes de acesso à informações, como "wifi" gratuito nas feiras, visto que essa ação almejada já é uma realidade em algumas feiras de Fortaleza, mas nem todas possuem essa infraestrutura pública como é o caso das feiras pesquisadas.

Portanto, as ações pretendidas ajudariam a minimizar o trabalho informal nas feiras, propiciando mais dignidade e melhores condições de desenvolvimento econômico a esses comerciantes.

\section{REFERÊNCIAS}

ALBERTIN, A. L. Valor Estratégico dos Projetos de Tecnologia de Informação. RAERevista de Administração de Empresas, v. 41, n. 3, São Paulo, 2001. http://dx.doi.org/10.1590/S0034-75902001000300005

ALBERTIN, A. L. Administração de informática: funções e fatores críticos de sucesso.5 ed. São Paulo: Atlas. 2004.

BRASIL. Constituição (1988). Constituição da República Federativa do Brasil: promulgada em 5 de outubro de 1988. 34a . ed. Brasília: Câmara dos Deputados, 2011.

Brasil DW/ Notícias e análises do Brasil e do mundo. Desemprego no Brasil cairá pela primeira vez desde 2014, prevê OIT. Disponível em: https://www.dw.com/ptbr/desemprego-no-brasil-cair\%C3\%A1-pela-primeira-vez-desde-2014-prev\%C3\%AA-oit/a42263300. Acesso em: 01 jul. 2018.

DEMO, Pedro. Pesquisa e construção do conhecimento: metodologia científica no caminho de Habermas. Rio de Janeiro: Tempo Brasileiro, 1994.

DOLABELA, Fernando. Oficina do empreendedor: metodologia de ensino que ajuda a transformar conhecimento em riqueza. 6 ed. São Paulo: Editora de Cultura 1999.

DOLABELA, Fernando. O segredo de Luísa. 30. ed. São Paulo: Cultura, 2006.

FINATI, Cláudio Roberto. O valor social do trabalho. Revista do Tribunal Regional do 
Trabalho da 15ª Região, São Paulo: LTr, n. 8, 1996.

GIL, A. C. Métodos e técnicas de pesquisa social. 6. ed. São Paulo: Atlas, 2008.

HORTA, Carlos Roberto (Org.). Globalização, trabalho e desemprego: processos de inserção, desinserção e reinserção: enfoque internacional. Belo Horizonte: C/Arte, 2001.

MAFRA, P. D. Camelôs cariocas. In: VELHO, G. (Org.) Cultura, política e conflito. Rio de Janeiro: Jorge Zahar, 2007.

MARCONDES, Reynaldo Cavalheiro e BERNARDES, Cyro. Criando empresas para o sucesso. 2 ed. São Paulo: Futura, 2000.

MOURA, Carolina Figueiredo de. Princípios constitucionais da ordem econômica. 2012. Disponível em: <https://www.webartigos.com/artigos/principios-constitucionais-da-ordemeconomica/90125/>. Acesso em: 26 jun. 2018

REZENDE, D; ABREU, A. Tecnologia da informação aplicada a sistemas de informação empresariais. São Paulo: Atlas, 2000.

SANTOS, Geórgia Patrícia Guimarães dos. Desemprego, informalidade e precariedade: a situação do mercado de trabalho no Brasil pós-1990. Pro-Posições versão On-line, 2008. ISSN 1980-6248. Vol.19, n.2. Disponível em: http://dx.doi.org/10.1590/S010373072008000200011.

SCHUMPETER, J. A. História da análise econômica. Rio de Janeiro: USAID, 2012.

SERVIÇO BRASILEIRO DE APOIO ÀS MICRO E PEQUENAS EMPRESAS (SEBRAE). Direitos e deveres do MEI. Disponível em:

<http://www.sebrae.com.br/sites/PortalSebrae/sebraeaz/direitos-e-deveres-

domei,b6d5d4361e3c8410VgnVCM2000003c74010aRCRD>. Acesso em: 23 junho. 2018.

SOUZA, Augusto Carvalho; FEIJÓ, Carmem Aparecida; SILVA, DB do N. Níveis de Informalidade na economia brasileira. Revista Econômica do Nordeste, Fortaleza, 2006. Versão On-line. ISSN 2357-9226. Vol. 37, n.3. Disponível em:

https://ren.emnuvens.com.br/ren/article/view/653.

WEBER, M. Conceito e categorias de cidade. In: VELHO, O. G. (Org.). O fenômeno urbano. Rio de Janeiro, Zahar, 1979. 